\title{
Research and Practice on Cultivating Innovative Ability of Pharmaceutical Graduate Students
}

\author{
Wufu Zhu, Caolin Wang, Shan Xu, Pengwu Zheng* \\ School of Pharmacy, Jiangxi Science \& Technology Normal University, Nanchang, China \\ zhengpw@126.com
}

\begin{abstract}
Innovation has traditionally been the focus of China and has the most potential for development. Similarly, master's graduate training must also consider the issue of innovation. However, the reform of our country's education and training model for graduate students has yet to be deepened. In our research, we combine the actual situation of undergraduate teaching, scientific research and graduate education in school of pharmacy, Jiangxi Science \& Technology Normal University. First of all, the graduate student of our research group was chosen as the research object of cultivating innovative ability. Subsequently, research and discussion on the training mode of innovative ability of pharmacy graduate students were started. In this research, the majority of graduate students, under the mode of co-mentor training, have significantly improved their academic performance during their study at school. The number of outstanding reports, in the opening report, mid-term evaluation and graduation reply, increased significantly, the number of published papers indexed by SCI increased by $50 \%$.
\end{abstract}

Keywords-Postgraduate student training; School of pharmacy; Innovation

\section{INTRODUCTION}

At present, the training model for postgraduate students in China is mainly academic and professional education [1-3]. Postgraduate education is a higher level of academic education than undergraduate education. Postgraduate education not only shoulders the task of mastering and promoting high-tech and training senior personnel, but also an important part of the national education [4-8]. In our country, postgraduate education has always been known as a task and means to raise the training level, which shows that our education does not pay enough attention to the issue of postgraduate innovation ability. There is also a one-sided understanding that since the country needs a large number of high-level personnel. Then, postgraduates will neither have an excessive number of problems in quantity nor an issue of quality of employment competitiveness. In addition, the lack of guidance and encouragement of policies not effectively inspire graduate students' innovative thinking, nor can they allow graduate students to devote more efforts to innovation activities [9]. Therefore, graduate students in our country generally have the problem of lack of innovative awareness.

There are many countries in the world of innovative training model worthy of our study and research. The United States Ranked first in the pharmaceutical innovation industry, and enjoyed the medical innovation to bring them a brilliant economy. American pharmacy graduate education mainly has the following characteristics [10-12]. First of all, the cultivation plan pays close attention to the needs of national economic and social development, and often combines basic research with applied research. Secondly, Students are required to strengthen coursework and achieve interdisciplinary and cross-cutting learning of basic theoretical knowledge such as chemistry, physiology, materials science, life sciences, informatics, etc. The last, to more fully consider the selection of graduate students, entrance examination scores not as the only standard for admission to graduate students, pay more attention to a comprehensive examination of students' abilities [13]. With its principle of teaching and scientific research, its rigorous academic atmosphere and its efforts in the spirit of scientific research, Germany has earned them the respect of their counterparts around the world and made them a global leader in the field of medicine.

To sum up, the innovation ability of graduate students in pharmacy in our country still needs to be improved and strengthened. Especially for pharmacy graduate students who need more professional Practical ability, innovation ability is particularly important. In our research, we carry out a research on the cultivation of innovative abilities of graduate students in four aspects: the training model of graduate students' innovative abilities, the system of cultivation and evaluation of innovative abilities, the system of training and managing innovation ability, and the mode of integrating production, education and research.

\section{METHODS}

The research object is 60 graduate students of Analytical chemistry and Pharmaceutical Chemistry in Jiangxi Science and Technology Normal University. All students are divided into 2 groups of 30 people each. One group teaches with new teaching methods and the other group use classical methods. In this study, graduate students' innovative abilities are mainly split into the following several kinds of abilities: logical thinking ability, ability to discover problems and solve problems In addition, the index system for evaluation of innovative ability of pharmaceutical postgraduates has been drawn up based on the ability of innovation foundation, knowledge innovation, academic communication and innovation practice. 


\section{A. The methods of literature discussion}

Each student is required to read the weekly professional literature and write a research report. The report asked to answer five questions: 1, the literature talked about what? 2 . What are the innovations in this document? 3, what is the result of this document? 4, there is no shortage of literature where? 5, the results of literature research on their own topic what is the help?

\section{B. Case study method}

Innovative thinking of students is inspired through the use of classic cases. For example, in the section on the relationship between drug activity and structure in pharmaceutical chemistry, the structural modification of quinolone antibacterial is taken as an example. Based on understanding the relationship between activity and compound structure, get students to take full advantage of their spatial imagination, organize students to discuss in depth, get everyone to come up with ideas, and then aggregate and document.

\section{Academic conference}

Organize students to participate in the research field related to national or world-class academic conference. After each meeting, graduate students should provide some of the views they have learned at the conference and summarize them. After the meeting, students are organized to hold seminars, which mainly discuss the theme of the meeting. Each student needs to post their own understanding of the topics and content of the meeting.

\section{Cooperative enterprise internship}

For the problems provided by cooperative enterprises, a group of three graduate students. Each group put forward their own team's solution. And according to their own programs, to solve practical problems. If the program does not work for the first time, it can put forward an improved solution to solve the problem within a week.

\section{Evaluation Methods}

Evaluation methods include the basic ability of innovation, the ability of knowledge innovation, the ability of academic innovation, the ability of practical innovation. The maximum mark is 100. Detailed evaluation system table in the following Table 1.

TABLE I. PHARMACOLOGY GRADUATE STUDENT INNOVATION ABILITY EVALUATION SYSTEM

\begin{tabular}{cll}
\hline A level of indicators & \multicolumn{1}{c}{ Secondary indicators } \\
\hline The basic ability of innovation $(\mathrm{Cb}, 10 \%)$ & 1. & Examination achievement (50\%)
\end{tabular}

The ability of knowledge innovation $(\mathrm{Ck}, 50 \%)$

The ability of academic innovation (Ca, 15\%)

The ability of practical innovation $(\mathrm{Cp}, 25 \%)$
3. Academic paper $(10 * \mathrm{IF})$

The maximum mark is $80 \%$

4. Research projects $(20 \%)$

5. Academic conference $(40 \%)$

6. Academic conference report $(60 \%)$

7. Experimental program $(50 \%)$

8. Question satisfaction (50\%)

\footnotetext{
NOTE: Personal Composite Score $(\mathrm{Cc})=\mathrm{Cb} * 10 \%+\mathrm{Ck} * 50 \%+\mathrm{Ca} * 15 \%+\mathrm{Cp} * 25 \%$; Innovative basic ability score $(\mathrm{Cb})=\mathrm{C} 1 * 50 \%+\mathrm{C} 2 * 50 \%$; Knowledge innovation score $(\mathrm{Ck})=\mathrm{C} 3 * 80 \%+\mathrm{C} 4 * 20 \%$; Academic innovation score $(\mathrm{Ca})=\mathrm{C} 5 * 40 \%+\mathrm{C} 6 * 60 \%$; Practical innovation score $(\mathrm{Cp})=\mathrm{C} 7 * 50 \%+\mathrm{C} 8 * 50 \%$

\section{RESULTS AND DISCUSSION}

The following chart shows the distribution of students' of each innovation ability index.
}

Two years later, both groups of students calculated the corresponding scores by the formula of the evaluation system. 


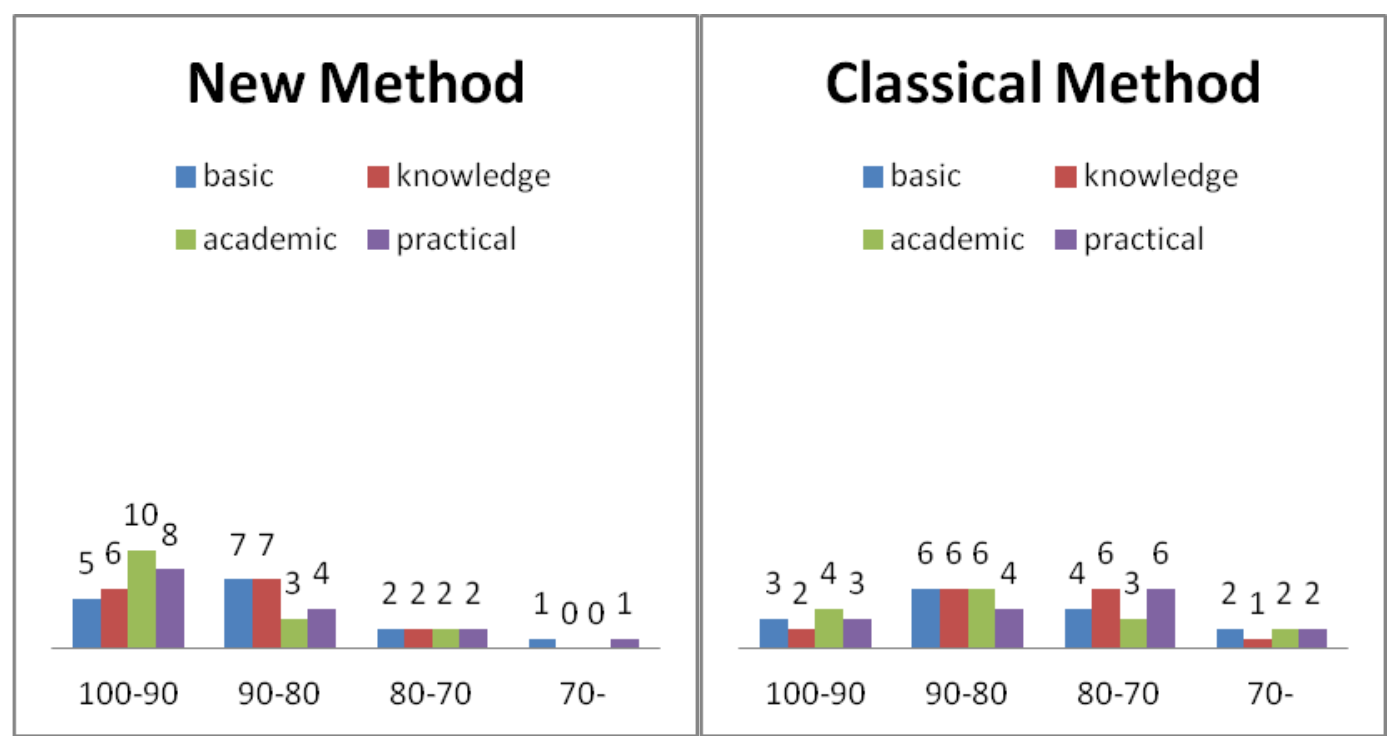

Fig. 1. Student a level of indicators score distribution

It is noteworthy that, in the evaluation of academic innovation, the new teaching method has 10 students in the overall score between 100-90. However, only 4 students in the traditional teaching method reached the level of 100-90. In addition, in terms of practicing innovative ability, 12 students achieved a grade of 80 or above, accounting for $80 \%$ of the total. This ratio is nearly $30 \%$ higher than the traditional teaching methods.
Look carefully, you will find that there is a marked increase in the number of academic articles published and applied for research projects by students who receive new methodological teaching.

These data demonstrate that the new method has achieved excellent results. Although, there is no significant advantage on the basic capabilities of innovation. However, there are noticeable differences in knowledge innovation ability, academic innovation ability and practice innovation ability.

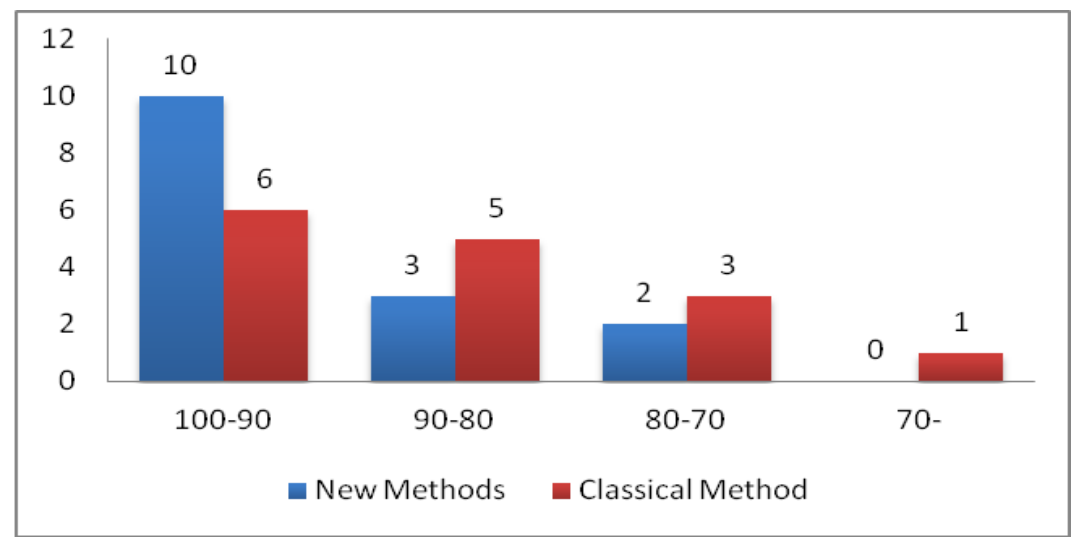

Fig. 2. Individual innovation ability comprehensive score distribution

Figure 2 shows the individual composite score of each graduate student's ability to innovate. All scores are the result of multiplying the total score of each category in Figure 1 by its absolute percentage and then adding the resulting scores. It is clear from the figure that none of the postgraduates under the new teaching methods have a personal comprehensive score lower than 70 . It is clear that $66.7 \%$ of the postgraduates have a combined score of 90 or above. Therefore, graduate students who accept the new method have a greater ability to innovate than the graduate students who receive traditional methods of education.

\section{CONCLUSION}

In this study, through the practice of research and practice in the cultivation of innovative abilities of postgraduates in pharmacy, it not only improves the ability of pharmacy graduate students to innovate on the one hand, but also encourages and cultivates students' ability of team cooperation, self-learning ability and application of theoretical knowledge Realistic problem ability. Thus, the overall quality of innovation of graduate students is improved. For the postgraduate training mode reform, laid a good experimental data foundation. 


\section{ACKNOWLEDGMENT}

We gratefully acknowledgment the generous support provided by the Academic Degrees \& Graduate Education teaching reform project of Jiangxi province (JXYJG-2017142\&JXYJG-2015-139).

\section{REFERENCES}

[1] Van Driel J H, Beijaard D, Verloop N. Professional development and reform in science education: The role of teachers' practical knowledge [J]. Journal of research in science teaching, 2001, 38(2): 137-158.

[2] Stoddard J J, Kindig D A, Libby D. Graduate medical education reform: service provision transition costs [J]. JAMA, 1994, 272(1): 53-58.

[3] Berman R A. Reform and continuity: Graduate education toward a foreign cultural literacy [J]. Profession, 1997: 61-74.

[4] [Thibault G E. Resident Empowerment as a Driving Theme of Graduate Medical Education Reform [J]. Academic Medicine, 2017.

[5] Xu J, Gong T. Preliminary Study on the Pharmacology Practical Teaching Reform in Pharmacy in Higher Vocational Colleges [J]. Asian Social Science, 2016, 12(8): 179.

[6] Romanelli F. Flexner, Educational Reform, and Pharmacy [J]. American Journal of Pharmaceutical Education, 2017, 81(2): 21.
[7] Arndell C, Proffitt B, Disco M, et al. Street outreach and shelter care elective for senior health professional students: An interprofessional educational model for addressing the needs of vulnerable populations [J] Education for Health, 2014, 27(1): 99.

[8] Trygstad T. Payment Reform Meets Pharmacy Practice and Education Transformation [J]. North Carolina Medical Journal, 2017, 78(3): 173176.

[9] Gubbins P O, Micek S T, Badowski M, et al. Innovation in clinical pharmacy practice and opportunities for academic-practice partnership [J]. Pharmacotherapy: The Journal of Human Pharmacology and Drug Therapy, 2014, 34(5)

[10] Ulbrich T R, Adams A, Bright D R, et al. Differences in career paths and attributes of pharmacists completing a community pharmacy residency program (CPRP) [J]. INNOVATIONS in pharmacy, 2014, 5(4): 1.

[11] Xiao B, Chankong V. Analysis on Influencing Factors on Cultivation of Graduate Innovation Ability Based on System Dynamics [C] International Symposium on Knowledge and Systems Sciences. Springer, Singapore, 2017: 250-266.

[12] Xie D, Zhang Y, Xiao J, et al. Training Graduate Students of the Computer Science and Technology Field in China [J]. Journal of Applied Science and Engineering Innovation, 2016, 3(2): 49-51.

[13] Jian F, Jing Z, Ai-Ling Q I, et al. Innovation Oriented Team Construction of Graduate Students [J]. D E Stech Transactions on Social Science, Education and Human Science, 2017 (mess). 